\title{
An Assessment of the Impact of Climate Change on Plant Species Richness Through an Analysis of the Normalised Difference Water Index (NDWI) in Mutirikwi Sub-catchment, Zimbabwe
}

\author{
Lazarus Chapungu ${ }^{1}$ and Luxon Nhamo ${ }^{2}$ \\ ${ }^{1 .}$ University of South Africa (UNISA), College of Agriculture and Environmental Sciences, \\ Preller Street, Muckleneuk Ridge, Pretoria, South Africa \\ 2. International Water Management Institute (IWMI), 141 Cresswell Street, Weavind Park, \\ Pretoria, South Africa \\ Email: lchapungu@gmail.com; Tel: +26377 2248931
}

http://dx.doi.org/10.4314/sajg.v5i2.11

\begin{abstract}
This study assesses the effects of climate change on vegetative species diversity exploring the usefulness of the Normalised Difference Water Index (NDWI) in predicting spatio-temporal diversity variations. The relationship between species richness and climatic variables of rainfall and temperature is explored based on species data collected from the field over a 3 year period and climate data collected from four local weather stations. Relationship between NDWI and species diversity indices is examined to confirm the usefulness of Remote Sensing in predicting vegetative diversity. The resultant predictive model was used to estimate changes in species richness over a 27 year period (1987-2014). The species diversity data was then regressed with climatic data for the same period. The results show a significant $(P<0.05)$ correlation between species diversity and the two climatic variables. The results also indicate that there is a significant positive $\left(P=0.0001 ; \alpha=0.05 ; R^{2}=0.565\right)$ relationship between species richness and NDWI. This implies that the NDWI is essential when assessing changes in species diversity over time. The Mann Kendall test revealed a decrease, though not statistically significant, in the rainfall received within the catchment over the period and significant variability. The minimum and maximum temperatures over the period were significantly increasing. These changes in climate variables were matched with a decrease in species richness. Some species tend to be succumbing to the environmental changes influenced by climate change resulting in their changes in phenology, abundance and distribution.
\end{abstract}




\section{Introduction}

Long term trend analysis of climatic elements of temperature and rainfall have shown that climate is indeed changing (Warburton and Schulze, 2005; Dore, 2005; Kruger and Shongwe, 2004; New et al., 2006; Warburton et al., 2005). The Earth's temperatures have increased by approximately $0.6^{\circ} \mathrm{C}$ over the past 100 years resulting in a warming trend (Walther et al., 2002; IPCC, 2002, Hansen, 2010). In Zimbabwe, temperatures have risen by approximately $0.8^{\circ} \mathrm{C}$ from 1933 to 1993 (Unganai and Mason, 2002). Rainfall has shown a declining trend that is not statistically significant, however, several studies (e.g. Makarau, 1995; Unganai, 1996; Mason and Jury, 1997; Mazvimavi, 2010); Simba et al., 2012) established that the decrease of rainfall in Zimbabwe has translated into a decline of up to 10\% on average over 100 years. Furthermore, Simba et al. (2012) postulated an increase in the number of seasons recording below normal rainfall over time.

The warming trends, in addition to increased rainfall variability are contributing to the observed changes in species distribution, composition, phenology and other diversity related characteristics (Hughes, 2000; Hannah, 2001; IPCC, 2001; Hannah et al., 2002; John et al., 2008). Climate change poses a challenge through intensifying the impacts of other pressures. It affects different ecosystems in different ways, depending on the complexity and original characteristics of the system, geographical location and presence of factors that may regulate the extent of the changes. Ladley et al., (2010) warn that climate change could exceed habitat destruction as the greatest hazard to biodiversity in the near future. Other studies (Perrings, 2010; Michelle et al., 2012) point to the fact that climate change has negatively affected and will continue to influence species richness and evenness.

Assessing the response of biodiversity to climate change has emerged as an active field of research (Parmesan and Yohe, 2003; John et al., 2008; Dillon et al., 2010; Gilman et al., 2010; Pereira et al., 2010; Salamin et al., 2010; Beaumont et al., 2011; Dawson et al., 2011; McMahon et al., 2011; Bellard et al., 2012). These studies are significantly contributing in informing scientists and decision makers about forthcoming threats of the changing climate on vegetative species. It further provides a means to bolster attribution of vegetative species changes to climate change and can support the formulation of strategic environmental policies and proactive programs to regulate climate change impacts on plant species diversity. However, the multiplicity of approaches and variability of results from these studies make it 
difficult to get a clear picture of the current impacts and future status of biodiversity under a changing climate.

In southern Africa in general and Zimbabwe in particular, there is still paucity of scientific understanding of climate change's impact on vegetative species diversity, specifically species richness. Several studies (Lenihan et al, 2003; Perrings, 2010; Bellard et al; 2012; Michelle et al., 2012) have claimed that climate change affects biodiversity but without focusing on specific diversity indices. This poses challenges when designing adaptive and mitigation strategies that are ecosystem and species specific.

Global climate models, regional climate models, dynamic and equilibrium vegetation models, species bioclimatic envelope models and site-specific sensitivity analysis are some of the tools that have been used to assess the impact of climate change on biodiversity (Sulzman et al., 1995). However, each of these tools has its weaknesses ranging from oversimplification of reality to complexity. This resulted in compromised reliability of results produced. In this study, satellite based remote sensing is tested to find out if we can have a way of understanding the impact of climate change on vegetation diversity through image analysis.

The normalised difference vegetation index (NDVI) has been widely used for remote sensing of vegetation for many years (Gao, 1996). This index provides a strong vegetation signal and good spectral contrast from most background materials. It provides an effective measure of photosynthetically active biomass. Previous studies have shown that NDVI can be used to ascertain species diversity (Skidmore et al, 2003; John et al, 2015, Walker et al, 1992). Mutowo and Murwira (2012) also confirm the importance of remotely sensed data in predicting spatial diversity of tree species in Savanna woodlands. However, to the knowledge of the author, no study has used remote sensing of vegetation liquid water to assess vegetative species diversity changes under a changing climate.

Some studies (Jackson et al., 2004, Gao, 1996) have already explored the potential of using reflectance data to estimate the vegetation water content (VWC). Vegetation species, due to their varying inter-cellular air spaces of the spongy mesophyll layer of leaves, contain different amounts of water depending on the type of species. Thus, differences in vegetation species can be detected through an analysis of their VWC. Gao (1996) developed the Normalized Difference Water Index (NDWI) to determine VWC based on physical principles. According to Jackson et al (2004), NDWI has proved useful in vegetation water content mapping and drought monitoring because the two spectral bands (NIR and SWIR) used in its 
calculation are responsive to changes in the water content and inter-cellular air spaces of the spongy mesophyll layer of leaves in the vegetation canopy.

Vegetative species differ in water content and inter-cellular air spaces in leaves. It is therefore assumed that NDWI is able to determine the variety of tree species in geographic space over time. This study assesses the utility of NDWI in determining the impact of climate change on vegetative species diversity. This objective is preceded by determination of existence of climate change in the catchment and assessment of how the changes are affecting vegetation diversity. The study was developed and tested in the Mutirikwi sub-catchment of Masvingo province of Zimbabwe.

\section{Materials and Methods}

\subsection{Study Area}

Mutirikwi catchment is one of the five sub-catchments within Runde River Catchment which is located at $20^{\circ} \mathrm{S}$ and $30^{\circ} \mathrm{E}$, in Zimbabwe. It occupies the central to southern parts of Zimbabwe. Figure 1 is a map of Zimbabwe showing the locations of Mutirikwi sub-catchment.

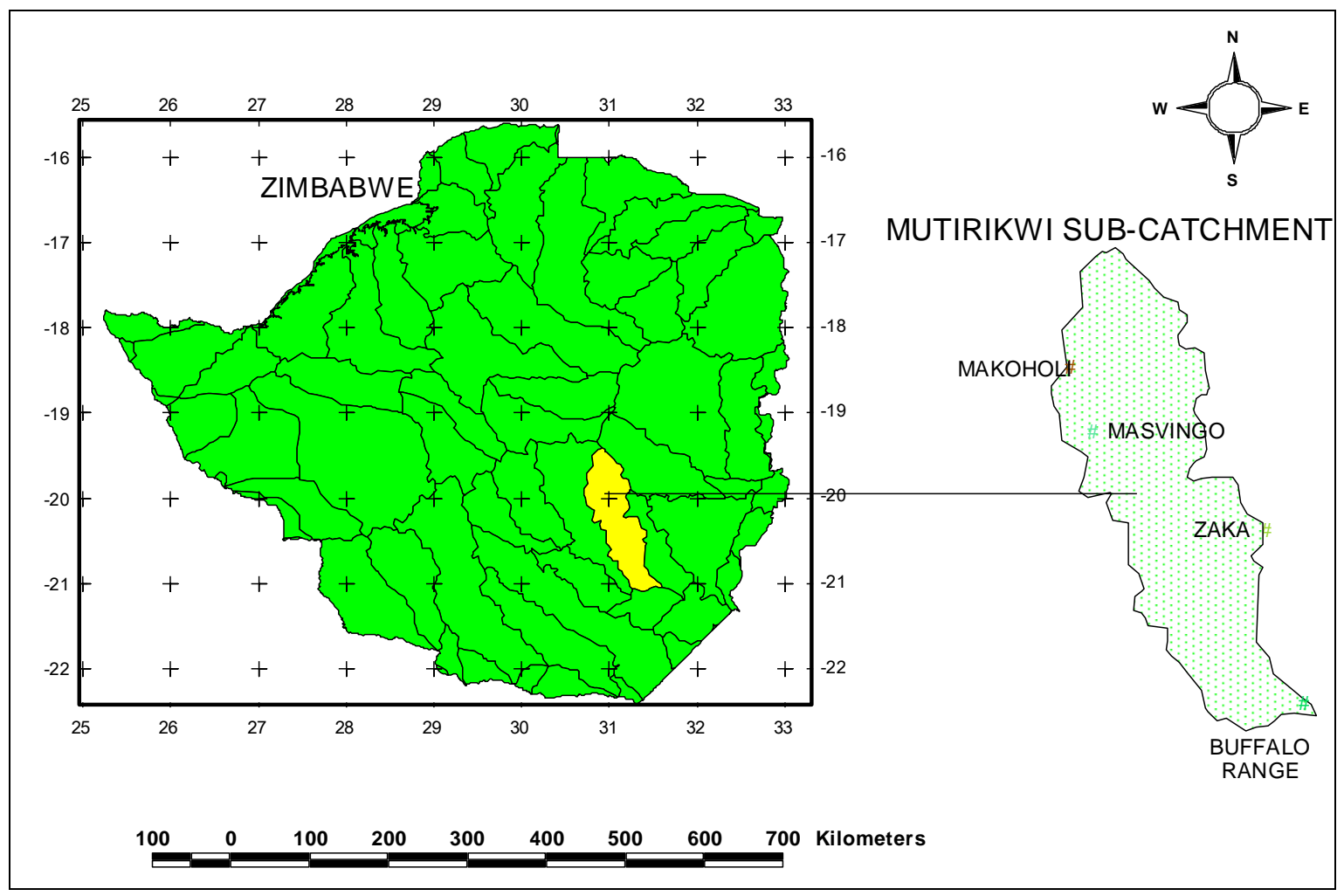

Figure 1. Mutirikwi sub-catchment and the weather stations used in the study (Produced by researcher) 
The area of the catchment, which is approximately $7419 \mathrm{~km}^{2}$, stretches from Serima to Triangle, covering parts of Gutu, Masvingo, Chiredzi and Zaka district. The topography is highly variable with gently undulating to rolling rock out-crops and dissections. Altitude ranges from $450 \mathrm{~m}$ to $1240 \mathrm{~m}$ above sea level.

The tree bush savannah is the most dominant type of vegetation with continuous or discontinuous grass cover being influenced by soil moisture regimes (Zhou, 2004). Vegetation species composition is mostly determined by rainfall pattern, topography, soil type and human disturbance. Miombo woodland mainly dominated by Brachystegia spiciformis, and Julbernardia globiflora, (Campbell et al, 2000), make part of woody vegetation in the northern parts of the catchment. The catchment falls in agro ecological zone III, IV and V where effective rainfall probability levels are very low (Bernardi and Madzudzo, 1990; Makadho, 1996). Mutirikwi sub catchment also experiences sub-tropical climate with distinct summer and winter seasons. The rainfall is highly variable and uncertain making it prone to droughts. High precipitation is received in summer between November and March and averages between $600 \mathrm{~mm}-800 \mathrm{~mm}$, annually. Temperatures are generally high with averages of up to $22^{\circ} \mathrm{C}$ per annum.

\subsection{Field Sampling and Data Collection}

A GIS based nested non-aligned block sampling design which permits multi-level assessment of variables at varied scales (Urban, 2002) was used to select the study units. It makes use of a grid as the basic template from which locations are randomly nested. Figure 2 shows the stages followed using this method.

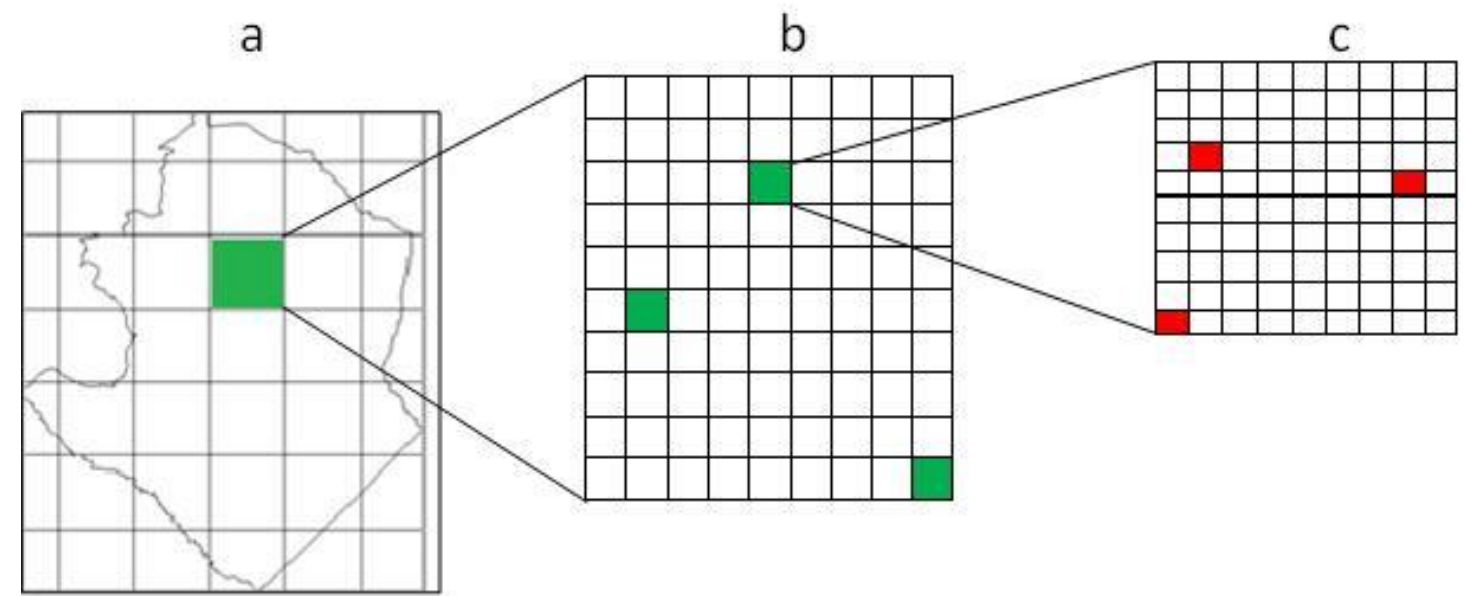

Figure 2. Stages followed using the nested non-aligned block sampling design 
First, grids of larger sizes were overlaid on Masvingo province map. All grids within the boundary of the province were selected and further subdivided into smaller grids. Second, 3 smaller grids were randomly selected. Third, the randomly selected grids were further subdivided and 3 final sampling locations were selected. This was done on satellite images of the study area using the Integrated Land and Water Information System (ILWIS) software. ILWIS is GIS software that processes remote sensing and other data to produce user defined outputs.

The coordinates of the centres of the selected grids were used for plot identification using a hand held Global Positioning System (GPS) receiver at less than 5m error. An inventory of vegetative species diversity was conducted within the study units (200 x 200m plots) using the Point Center Quarter Method (PCQM) (Mitchell, 2007). The technique involved the observer moving along a transect line in a predetermined direction within a randomly selected quadrat recording data at predetermined intervals. Figure 3 shows the plot and transect lines constructed at regular intervals of $40 \mathrm{~m}$ from which measurements were done.

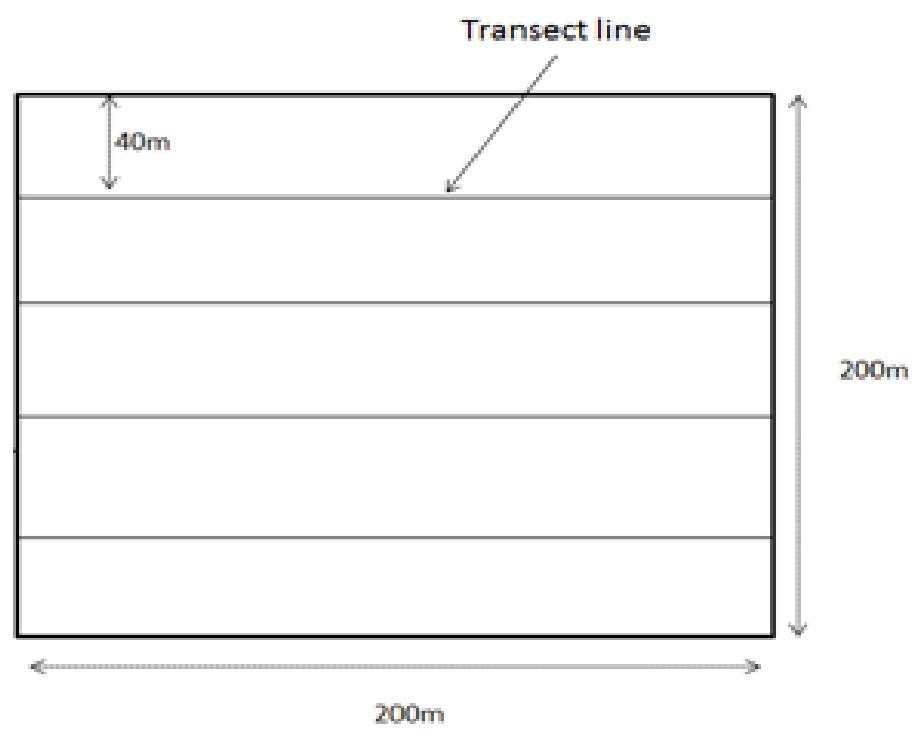

Figure 3. The $200 \times 200 \mathrm{~m}$ plot and transect lines produced in the study

A 200m transect line in each selected sampling plot was followed and measurements were done at every $40 \mathrm{~m}$ intervals. At each sampling point the tree nearest to the transect line, its height, width at breast height were recorded together with the distance as illustrated in Figure 4. 


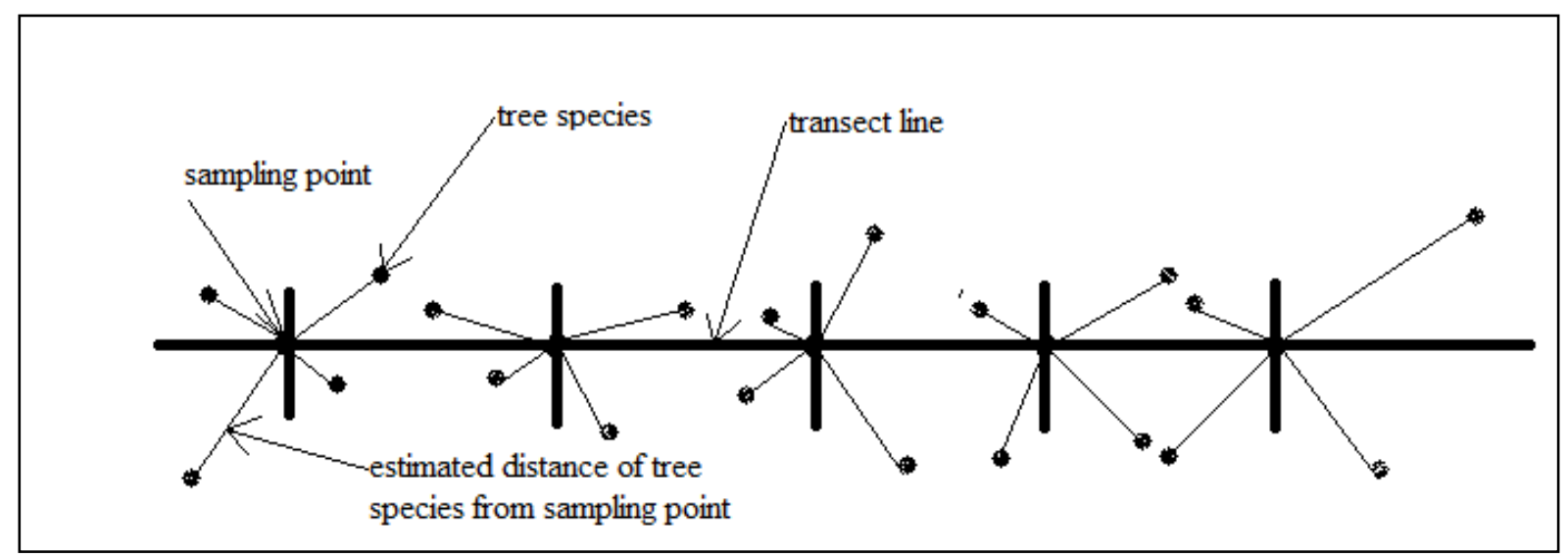

Figure 4. Sampling points along the transect line (produced by researcher)

A total of 25 sampling plots were established throughout the study area using the nested design sampling technique. Each sampling plot had a total of 36 sampling points from which measurements were done to determine species richness and other diversity parameters. Species richness was determined by counting the number of vegetative species within the sampling plots and recording on data collection sheets.

\subsection{Satellite Image Pre-processing}

Landsat 8 Thematic Mapper imagery with spatial resolution of $30 \mathrm{~m}$ was used. Images for December 1987, December 1998, December 2006 and December 2014 were acquired from the online Landsat archive via GloVis web-link. The year for the first imagery was determined by the availability of imagery with bands necessary to calculate NDWI. The selection of years was also determined by the availability of free imagery from the Glovis web link. The study however ensured that the selected imagery are distributed across specific decades e.g. between 1980 and 1990, 1990 and 2000, 2000 and 2010, 2010 and 2020 and it was ensured that there is a gap of more than 8 years between the years. The Landsat images were acquired in digital number (DN) format and calibrated to spectral radiance units ( $\mathrm{W} m-2 \mathrm{sr}-1 \mu \mathrm{m}-1$ ). The algorithm developed by Chander et al. (2009) specifically for calibrating Landsat images and the calibration coefficients were provided together with the respective Landsat image files as metadata files as shown in Equation 1:

$$
L_{\lambda}=\left(\frac{\operatorname{Lmax}_{\lambda}-\operatorname{Lmin}_{\lambda}}{Q \operatorname{calmax}-Q \operatorname{cal} \min }\right)(Q \operatorname{cal}-Q \operatorname{calmin})+\operatorname{Lmin}_{\lambda}
$$


Where $Q C A L$ is the calibrated and quantized scaled radiance in units of digital numbers, $\operatorname{Lmin}{ }_{\lambda}$ is the spectral radiance at $Q C A L=0, \operatorname{Lmax}_{\lambda}$ is the spectral radiance at $Q C A L=Q C A L M A X$, and QCALMAX is the range of the rescaled radiance in digital numbers. The conversion from DN to spectral radiance was done by implementing the Chander et al. (2009) algorithm using the Environment for Visualizing Images (ENVI) software.

The relationship between NDWI and species richness was examined to confirm the utility of remote sensing in predicting vegetative diversity. NDWI was calculated using the formula shown in Equation 2 (Gao, 1996):

$$
\mathrm{NDWI}=\frac{\rho N I R-\rho S W I R}{\rho N I R+\rho S W I R}
$$

Where $\rho N I R$ and $\rho S W I R$ are the reflectances of the near-infrared $(N I R, 0.78-0.89 \mathrm{~m})$ and shortwave-infrared (SWIR, 1.58-1.75m) regions, respectively.

\subsection{Rainfall and Temperature Data}

Seasonal total rainfall, mean minimum and mean maximum temperature data for Makoholi, Masvingo, Zaka and Buffalo range weather stations which span from 1971/72 to 2009/10 seasons were obtained from the Meteorological Services Department of Zimbabwe and used in this study. The location and distribution of these weather stations within the study area is indicated on the map shown on Figure 2. Mean minimum and maximum temperature data for the province were derived from minimum and maximum daily air temperatures, averaged over a year. The two elements (rainfall and temperature) were selected based on availability of the data. The data were used to determine the presence of trends and assess whether the trends were statistically significant or not.

\subsection{Data Analysis}

Time series data were subjected to distribution tests using the Kolmogorov-Smirnov test to ascertain how the data satisfy assumptions of parametric or non-parametric statistical analysis methods (Chikodzi and Mutowo, 2014). Lettenmaier, (1976) and Hirsch et al., (1993) noted that, unless the assumption of normal distribution for parametric statistics is met, it is generally advisable to use non-parametric tests. Non-parametric statistical analysis methods were therefore used in the study. 
Species data collected from the field and rainfall data collected from the meteorological office were analysed using the Statistical Package for Social Scientists (SPSS) software. Rainfall data were first interpolated using the nearest neighbour analysis in a GIS to ensure that all sampling plots are represented with rainfall data.

\subsection{Auto-correlation and Pre-whitening}

The Mann-Kendall (MK) test (Mann, 1945) was used to test if there was a significant change in rainfall and temperature patterns in Mutirikwi sub-catchment over time. The MK test is a non-parametric method to determine trends in time series data. Dietz and Kileen; (1981); Hirsch et al., (1993) concur that the test is simple, robust, can cope with missing values, and seasonality and values below detection limit. An add-in of Microsoft excel, XLSTAT 2015 was used to carry out this test.

However, prior to this test, the data was first tested for autocorrelation to ascertain the need for pre-whitening. Detection of auto-correlation would require the data to be prewhitened. Hamed and Rao (1998) put forward that auto-correlation is the correlation of a time series with its past and future values. Geophysical time series are frequently auto-correlated because of inertia or carryover processes in the physical system (Hamed and Rao, 1998). This confounds the application of statistical tests by reducing the number of independent observations thereby increasing the chances of detecting significant trends even if they are absent and vice versa. Pre-whitening is the process of removing undesirable autocorrelations from time series data prior to analysis. Thus, the data was pre-whitened in Paleontological statistics (PAST 3.0) software using the Autoregressive Integrated Moving Average (ARIMA) model (Hamed and Rao, 1998).

The ARIMA model performs time series forecasting and smoothening and project the future values of a series based entirely on its inertia. It takes into account trends, seasonality, cycles, errors and non-stationary aspects of a data set when making forecasts. It reduces residuals to white noise in the time series hence removing the possibility of finding a significant trend in the Mann-Kendall test when actually there is no trend (Von Storch, 1995). 


\section{Results and Discussions}

\subsection{Climatic Trend in Mutirikwi Sub-catchment}

\subsubsection{Rainfall}

The Mann-Kendall test shows that there is no significant trend $(\mathrm{P}>0.05)$ in rainfall amount received in the province over 30 years. All the four stations had no significant change $(\mathrm{P}=0.336,0.276,0.232,0.826,0.880 ; \alpha=0.05$ for Zaka, Buffalo range, Makoholi and Masvingo respectively) in seasonal total rainfall received. Figure 5 shows the trends for the four stations in the sub-catchment.

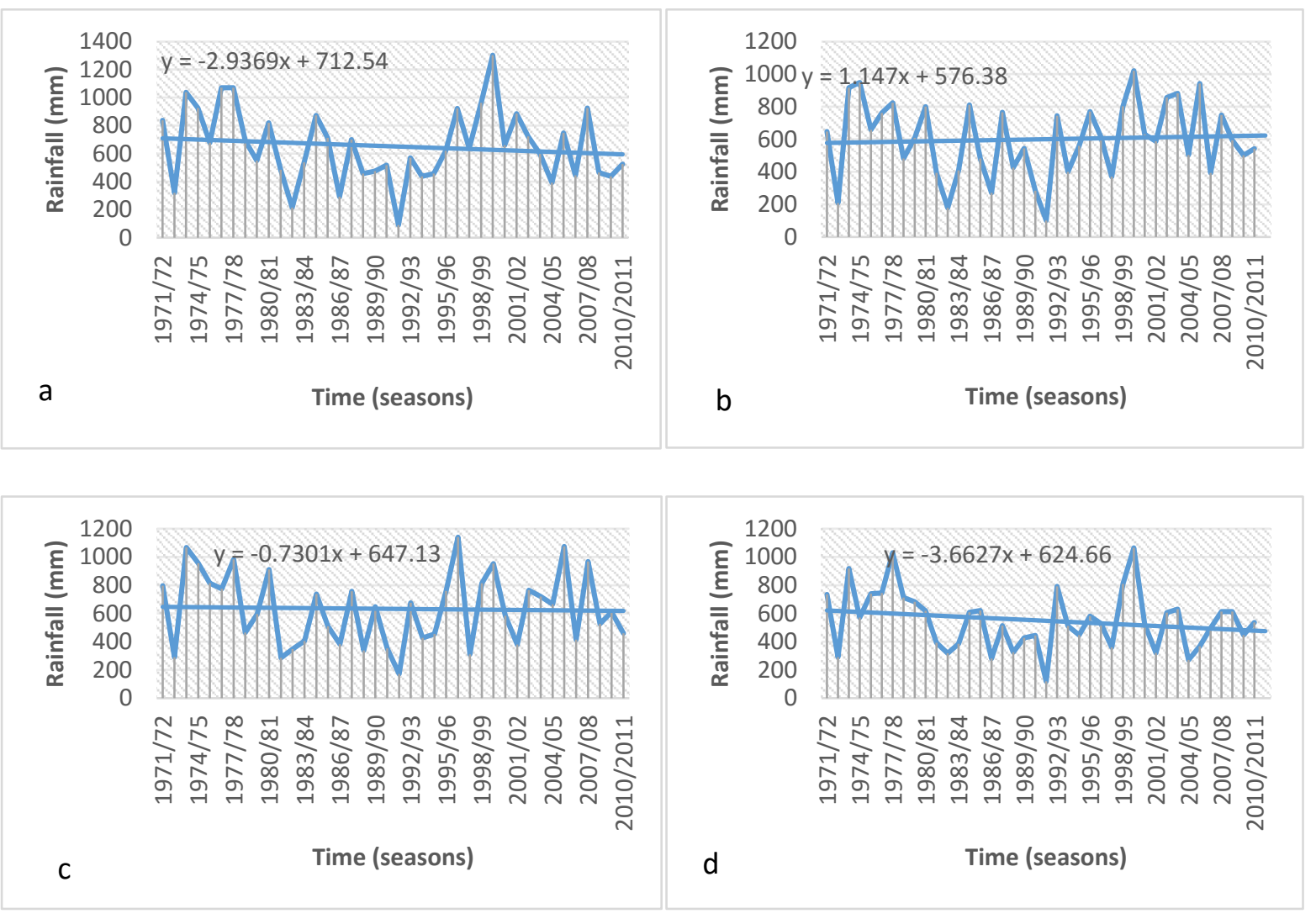

Figure 5. Seasonal total rainfall for the four weather stations used in the study: a Zaka, b. Masvingo, c. Makoholi and d. Buffalo range

Though the decrease is not statistically significant as revealed by trend tests, a visible trend showing a decline in rainfall can be regarded as climatic change as this has significant environmental impacts. Some species in an ecosystem are sensitive to slight changes in environmental gradients. Table 1 summarises the Mann Kendall trend tests for the four stations. 
Table 1. Results of the Mann Kendall trend tests showing the decrease of rainfall at the four stations

\begin{tabular}{lccccc}
\hline $\begin{array}{c}\text { Rainfall } \\
\text { Station }\end{array}$ & $\mathbf{H}_{\mathbf{0}}$ & $\begin{array}{c}\text { Mann } \\
\text { Kendall trend } \\
\text { test (P-Value) }\end{array}$ & $\mathbf{H}_{\mathbf{0}}$ Decision & $\begin{array}{c}\text { Risk of rejecting } \\
\mathbf{H}_{\mathbf{0}} \text { while true } \\
\mathbf{( \% )}\end{array}$ & Trend description \\
\hline Masvingo & No trend & 0.88 & Fail to reject & 88.05 & Not significant/ declining \\
Buffalo Range & No trend & 0.232 & Fail to reject & 23.2 & Not significant/ declining \\
Makoholi & No trend & 0.826 & Fail to reject & 82.6 & Not significant/ declining \\
Zaka & No trend & 0.336 & Fail to reject & 33.6 & Not significant/ declining \\
\hline
\end{tabular}

As shown in Table 1 there is no significant change in annual rainfall totals in Mutirikwi subcatchment. However, it should be noted that annual total rainfalls for the stations show decreasing trends in rainfall as indicated by the graphs in Figure 5. The graphs also show that rainfall is highly variable in the sub-catchment showing highs and lows along the years. The decreasing trend and the picks are indicator of climatic change and variability. These changing climatic conditions and variability are impacting negatively on the vegetative species ecosystems promoting changes in their diversity. This is in line with the Zimbabwe rainfall situation (Unganai and Mason, 2002). In most cases the decreasing rainfall amount has not been adequate to support the growth and health of certain species and ecosystems resulting in declining species diversity. The trend tends to show a continuous decline in species richness. While Christensen et al. (2007) argue that there is uncertainty on the magnitude of climate change impacts on rainfall in Southern Africa, this study indicates that climate change is taking place as shown by the decreasing rainfall and that decrease in itself constitutes climate change. These findings are in concurrence with those of IPCC (2007), which observed that rainfall patterns is Southern Africa are experiencing a declining trend and this is part of the evidence that the region is being affected by climate change.

Inter-annual rainfall variability exhibited in Figure 5 has been regarded as one of the proxy indicators for climate change. This has a propensity for influencing phenological characteristics of vegetation and contributes to changes in genetic, species and ecosystem diversity. These findings are augmented by Kusangaya et al., (2013) who indicated that there is robust scientific evidence pointing to an increased inter-annual variability, with extremely wet periods and more intense droughts and this constitutes climate change. This also concurs with Christensen et al., (2007)'s view that besides volumes, rainfall patterns are also expected to change in intensity and frequency, resulting in more extreme events and longer periods between rainfalls. These climatic perturbations are symptomatic to climate change and have a 
bearing on diversity of vegetative species. Kusangaya et al., (2013) avers that many models project that by 2050 the interior of Southern Africa will experience decreased rainfall during the growing season due to reductions in soil moisture and runoff. This might have implications on the distribution, abundance and phenology of rainfall dependent species.

It is the submission of this study that rainfall patterns in Mutirikwi sub-catchment is contributing to changes in vegetative species diversity. In trying to keep up with the changing rainfall patterns that show cyclic variation over time, individual species respond through time on a seasonal basis. Such responses will mainly affect the phenology of the species and in the process some may fail to produce adequate biomass. These assertions are in concurrence with Parmesan (2006)'s findings that the timing of life cycle events such as flowering, fruiting and seasonal migrations are the most ubiquitous responses to $20^{\text {th }}$ century climate warming. In a meta- analysis of a wide range of species including animals and plants, Root et al., (2003) agrees to these observations by claiming that the mean response across all species was a shift in key phenological events of 5.1 days earlier per decade over the last 50 years. These phenological changes can increase asynchrony in insect -plant systems which may lead to species extinction. Such extinctions will lead to the spatio-temporal changes in species richness.

\subsubsection{Temperatures}

The study also analysed temperature patterns in Mutirikwi sub-catchment to ascertain changes that have been taking place along the years and determine impact on species richness. Temperature is one of the most important climatic elements used by the majority of climate scientists in detecting the climate change phenomenon. The Seasonal Mann-Kendall trend test revealed statistically significant $(p=0.001, \alpha=0.05)$ changes in mean temperatures in Mutirikwi sub-catchment. The null hypothesis was that there is no trend in the temperature data. The null hypothesis was rejected and the tests show that the risk of rejecting it while it is true is $0.14 \%$. 
Figure 6 is a graph showing the trend in mean maximum temperatures expressed in seasons and mean minimum temperatures from 1951 to 2002.

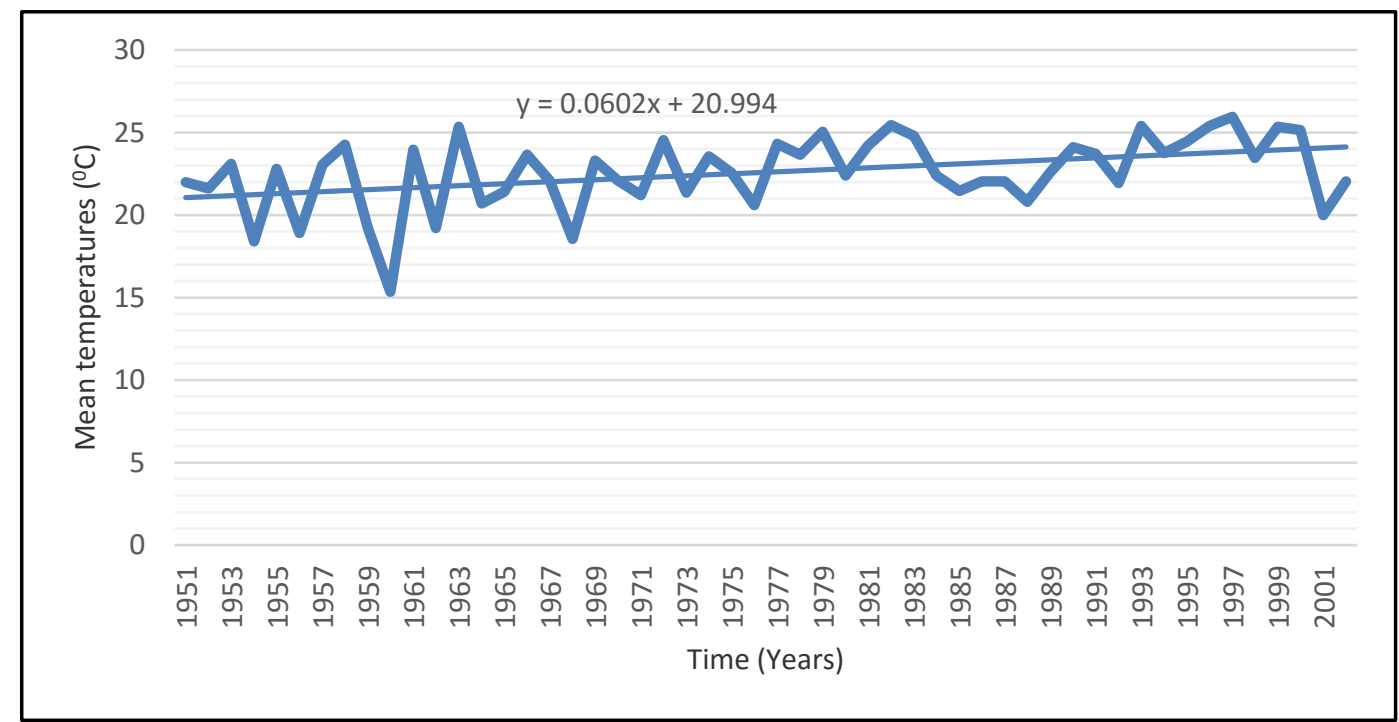

Figure 6. Mean temperatures for Mutirikwi sub-catchment between 1951 and 2001

As shown in Figure 6, the mean temperatures for the sub-catchment are increasing with increasing time and the increase is statistically significant $(\mathrm{P}<0.05)$. This indicates that the change in mean temperatures is contributing to environmental changes that are influencing species diversity in the sub-catchment. The increase in temperatures is leading to changes in species richness. Species tolerance to environmental gradients such as temperature vary depending on the type of species. Some species can cope with changing temperature patterns by adapting themselves to the new conditions in their local range, rather than by tracking their current optimal conditions in space or time. They go through physiological alteration to allow tolerance to warmer conditions. These findings are buttressed by Bellard et al., (2012) who also argues that some species undergo behavioural modification under climate change and this includes changes of energy budget. Tewksbury et al., (2008) claim that growth and reproduction are temperature dependent, therefore any temperature changes will result in changes in growth and reproduction patterns with consequent changes in species diversity.

\subsection{Relationship Between Species Richness and Climatic Variables}

Temperature and rainfall are the climatic variables most used by researchers to detect climate change (Lenihan et al., 2003; Simba et al., 2012). This study analysed the relationship between species richness and these variables to determine the effect of climate change on 
species richness. The existence of a relationship helps validate the utility of indices like the NDWI, calculated from remotely sensed data in predicting species richness.

Correlation analysis shows a strong positive relationship $(\mathrm{r}=0.794, \alpha=0.05)$ between seasonal total rainfall and species richness. An analysis of variance also indicate a significant relationship between the two variables $(\mathrm{P}=0.013, \alpha=0.05)$. The predictive model shows that the probability of accurately predicting species richness from seasonal total rainfall is high $\left(\mathrm{r}^{2}=0.645\right)$. The predictive model states that:

$S R=(4.53681160539723+1.00820882406886-0.2) \operatorname{STR}$

Where $S R$ is species richness and STR is the seasonal total rainfall

Figure 7 shows the graph produced in SPSS using interpolated rainfall data and species richness data collected from sampling plots to depict the relationship between species richness and seasonal total rainfall.

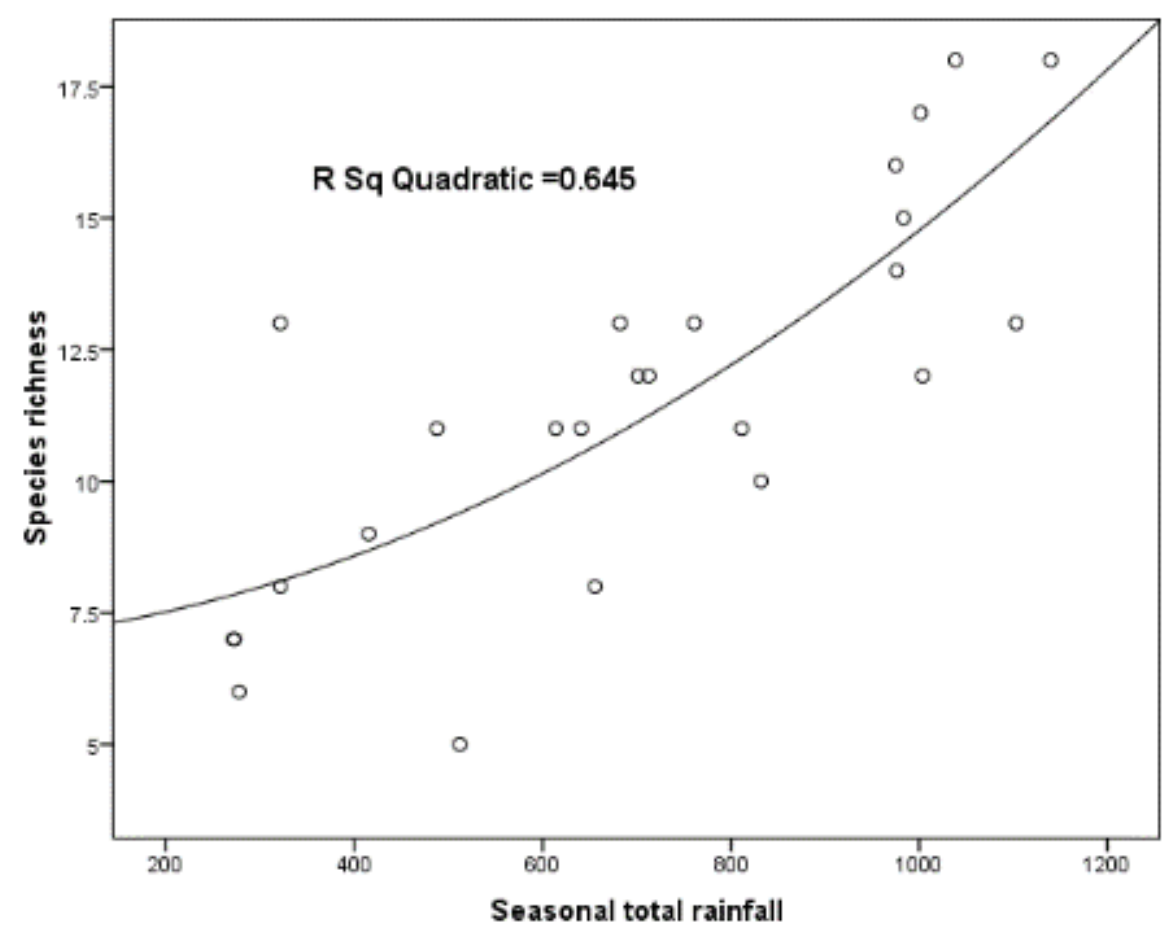

Figure 7. Species richness as a function of seasonal total rainfall in Mutirikwi sub catchment

As shown in Figure 7, species richness in Mutirikwi sub-catchment is dependent on the total seasonal rainfall. Total seasonal rainfall determines water availability for plant uptake. Water availability plays an important role in limiting or promoting plant biological and ecosystem processes (Ellis et al., 2001; Sala et al., 1997). Different plant life forms use water from different soil layers with different intensity. As a result of climate change, grasses and woody 
species in Mutirikwi sub-catchment have been invaded by desert shrubs which use less water. This results in changes in vegetative species diversity, specifically species richness. These findings concur with the views of other researchers (Schlesinger and Ehleringer, 2001; Schenk and Jackson, 2002; Snyder and Williams, 2003) who found that the decline in rainfall and the occurrence of droughts have resulted in the invasion of grasslands with desert shrubs consequently changing the diversity status of these ecosystems.

The relationship between species richness and temperature was also examined. Spearman's rank correlation analysis shows a strong negative relationship $(r=-0.686, \alpha=0.05)$ between species richness and seasonal maximum temperatures. Analysis of variance indicate a significant relationship ( $\mathrm{p}=0.00, \alpha=0.05)$ between the two variables. The regression model shown in Equation 4 shows that the probability of correctly predicting species richness from seasonal maximum temperatures is moderate $\left(\mathrm{R}^{2}=0.516\right)$.

$S R=(26.4273285914055-0.589508929365675) \mathrm{SMT}$

Where $S P$ is species richness and $S M T$ is seasonal maximum temperature.

Figure $8 \mathrm{a}$ is a graph produced in SPSS using interpolated seasonal maximum temperature data and species richness data collected from sampling plots to depict the relationship between species richness and seasonal maximum temperatures.

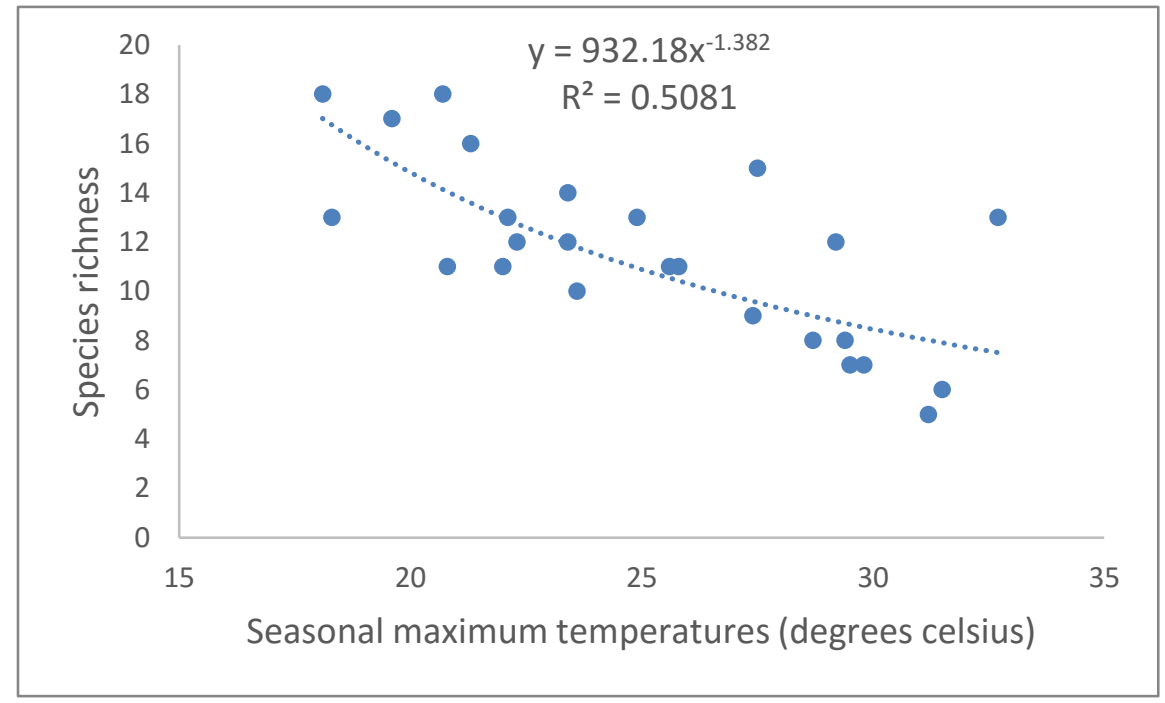

Figure 8a. Relationship between species richness and seasonal maximum temperatures 


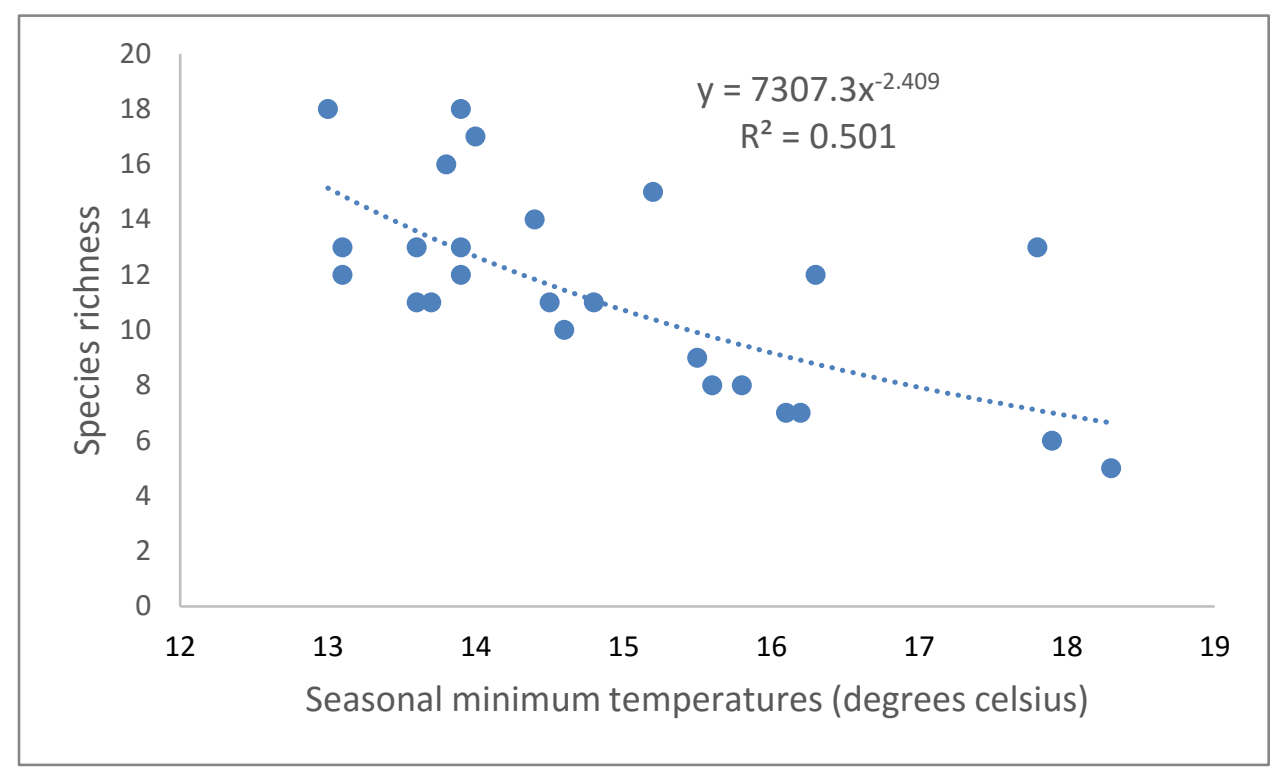

Figure $8 \mathrm{~b}$. Relationship between species richness and seasonal minimum temperatures A strong negative correlation $(\mathrm{r}=-0.612, \mathrm{P}=0.05)$ is also shown between species richness and seasonal minimum temperatures. There is also a significant relationship $(\mathrm{P}<0.05)$ between these variables and the $\mathrm{R}^{2}$ is 0.438 . Figure $8 \mathrm{~b}$ graphically illustrates this relationship.

As shown in Figure 8 regression of species richness by seasonal maximum and seasonal minimum temperatures shows a significant relationship between species richness and temperatures. It is indicated that species richness is decreasing with increasing temperatures. As highlighted earlier, growth and reproduction are temperature dependent. It appears that in Mutirikwi sub-catchment most species are becoming less tolerant to increased temperatures combined with declining total seasonal rainfall. However, the influence of climatic variables cannot not be overemphasised. The contribution of human activities and other related factors in regulating species richness should not go unnoticed.

\subsection{Species Richness and NDWI}

Spearman's rank correlation analysis reveals a strong positive correlation $(\mathrm{r}=0.759$, $\alpha=0.05$ ) between species richness and NDWI. An analysis of variance show that species richness can significantly be predicted $\left(\mathrm{R}^{2}=0,565, \mathrm{P}=0.0001, \alpha=0.05\right)$ from NDWI. Figure 9 shows the regression of species richness by NDWI. 


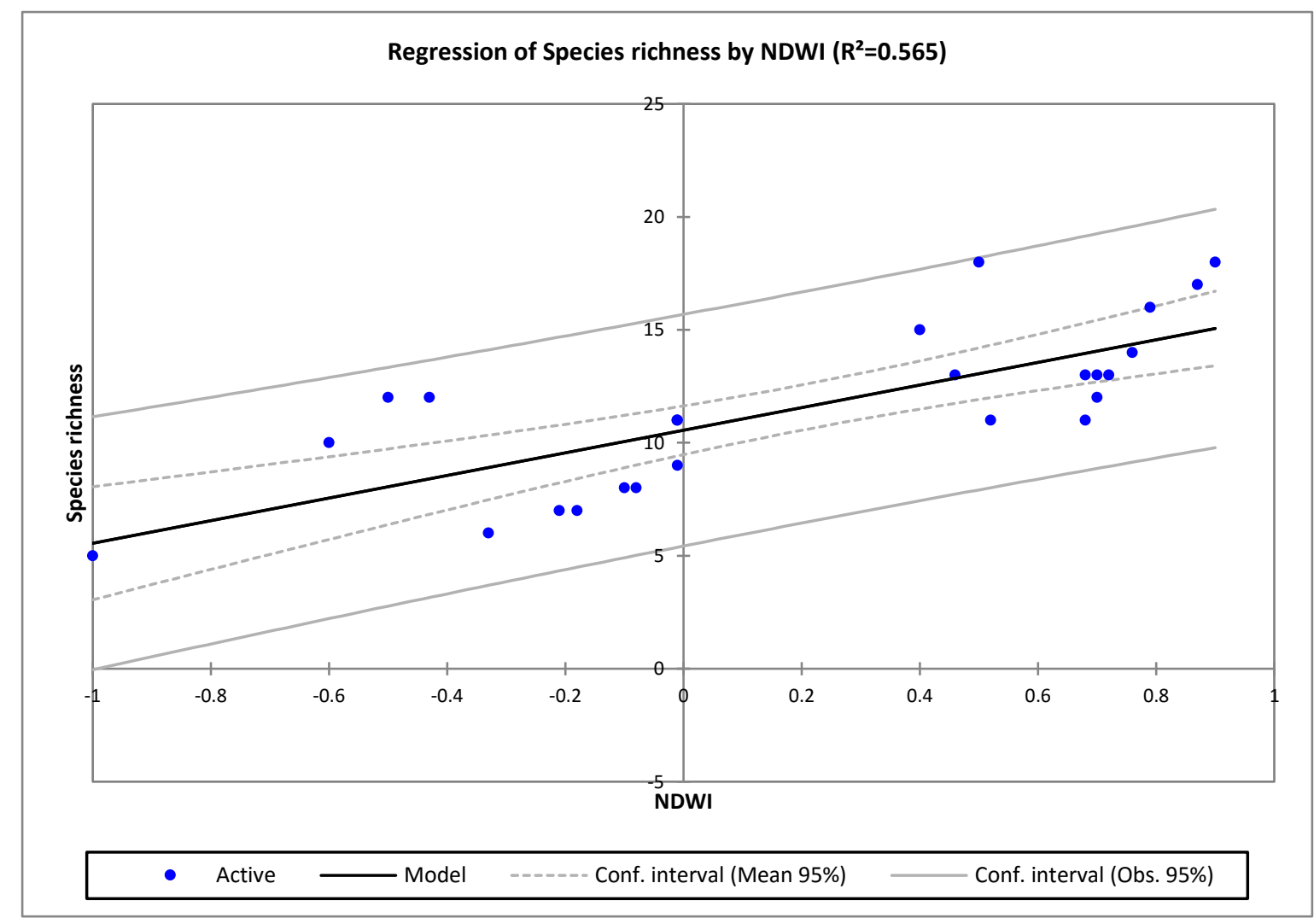

Figure 9. Relationship between species richness and NDWI

As observed from Figure 9, the coefficient of determination between species richness and NDWI is positive and reflects a strong relationship $\left(\mathrm{R}^{2}=565\right)$ between the two variables. The implication of this relationship is that NDWI can be used as an important remote sensing product to assess changes in species richness over time.

NDWI is sensitive to changes in liquid water content of vegetation canopies. Jackson et al. (2004) showed that this index is useful in vegetation water content mapping and drought monitoring because the two spectral bands (NIR and SWIR) used in its calculation are responsive to changes in the water content and inter-cellular air spaces of the spongy mesophyll layer of leaves in the vegetation canopy. Vegetative species differ in water content and intercellular air spaces in leaves. It is therefore possible that NDWI is able to determine the variety of tree species and can be used to detect the spatial and temporal impact of climate change on species diversity, specifically species richness.

While there is scarcity of studies that have focused specifically on NDWI as a proxy indicator of vegetative species diversity, a plethora of studies have highlighted the prowess of satellite based remotely sensed data in predicting species diversity. For example, Walker et al (1992) found a positive relationship between plant species richness and aggregated Normalised 
Difference Vegetation Index (NDVI) in California. Skidmore et al., (2003) established a unimodal relationship between species richness and NDVI.

While NDWI has been successfully used in predicting climate change impacts on species richness, it is not a better predictor of species richness compared to climatic elements indices of precipitation and temperature.

\subsection{Vegetative Species Diversity Changes Over Time}

Results have shown the potential of NDWI as a proxy indicator for species richness. In this study, NDWI was calculated for four different years but in the same month over a 27 year period to assess the changes in species richness using NDWI. The year interval was mainly determined by availability of satellite images for a specific year. However, it was ensured that there is an interval of more than 8 years. Figure 10 shows NDWI calculated for the years December 1987, December 1998, December 2006 and December 2014.

In 1987, a greater percentage of Mutirikwi sub catchment had positive NDWI values. Positive values indicate high species richness while the opposite is true for negative NDWI values. In 1989 the percentage of positive NDWI slightly increased due to high rainfall received. The trend continues to show a decrease in NDWI until 2014 for the same month of December. This study established a positive correlation between NDWI and species richness. Thus, Figure 10 implies that species richness is decreasing with time indicating that species richness is a function of climatic variables, primarily rainfall and temperatures. This implies that a change in the climatic variables may result in a change in species richness. Thus, the NDWI can be used to assess the impact of climate change on species richness. 

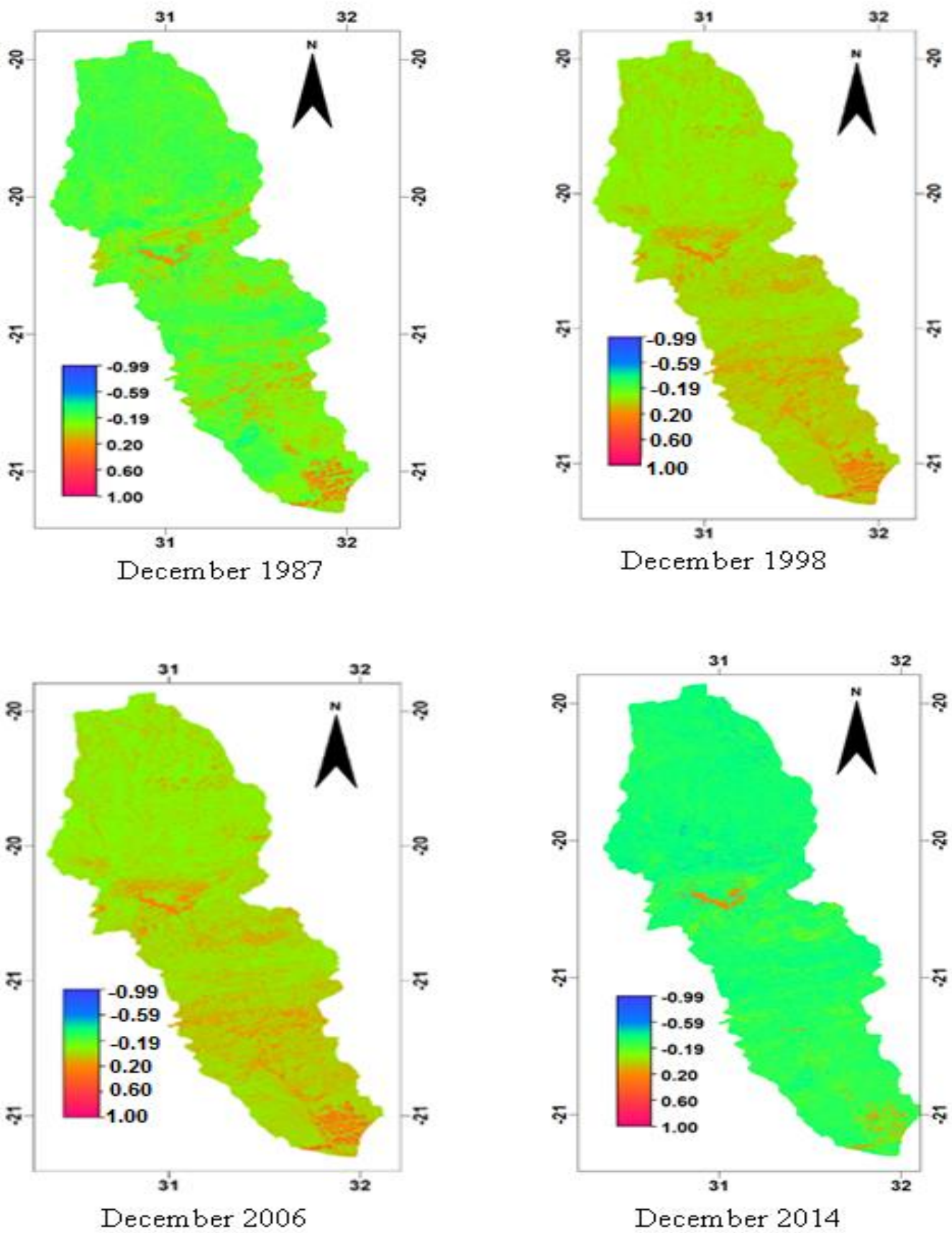

Figure 10. NDWI maps depicting changes in species richness over time

The colours on the images shown in Figure 10 represent the NDWI values for each pixel. Blue pixels have low values, green have moderate while red values indicate high NDWI values. However, there are some water bodies that are also showing high NDWI values.

Figure 11 reinforces the findings that species richness is declining with time as depicted by changes in NDWI values with an increase in time. NDWI has been successfully used to assess changes in species richness in this study. 


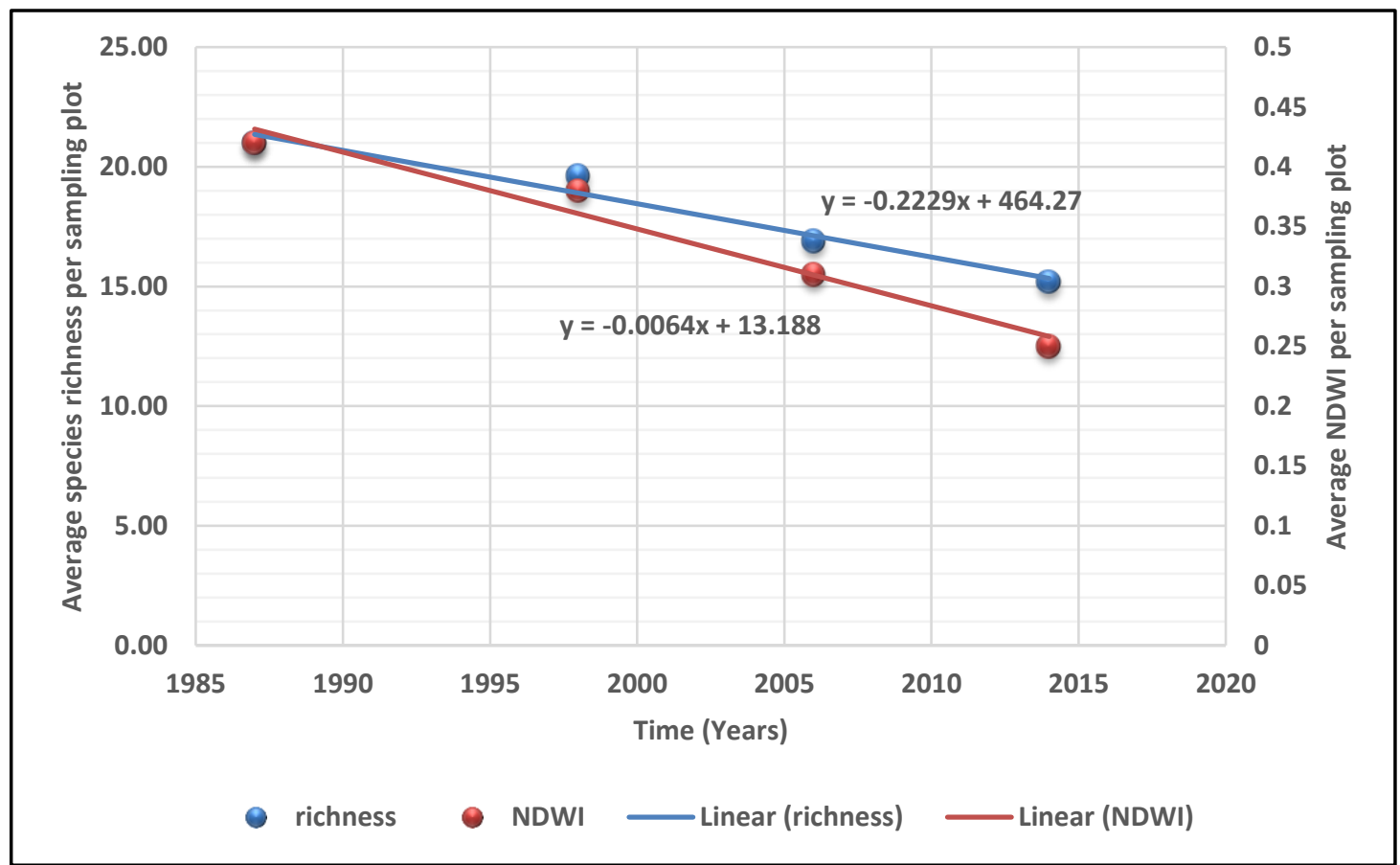

Figure 11: Changes in species richness over time due to changes in environmental gradient of temperature and rainfall depicted by changes in NDWI

As shown in Figure 11, as average species richness per sampling plot decreases with time, average NDWI per sampling plot is also decreasing. It has also been established that changes in climatic variables is related to changes in species richness over time, a view also confirmed by Bellard et al., (2012) and Parmesan, (2006) who aver that the multiple components of climate change are anticipated to affect all the levels of biodiversity, from organism to biome levels. They added that climate change has effects on individuals, populations, species, ecological networks and ecosystems. Climate change, thus decreases the genetic diversity of vegetation population by directional selection and rapid migration, which in turn affects ecosystem functioning and resilience. The relationship between species richness and NDWI shows that NDWI can contribute significantly to the understanding of the impact of climate change on species richness.

\section{Conclusion}

Temperatures are increasing and rainfall amount declining in Mutirikwi sub-catchment, thereby affecting vegetative species richness. Although the change in seasonal total rainfall is not statistically significant, a declining trend has significant environmental consequences. There is a significant increase in the inter-annual variability of the climatic elements that have been punctuated by extreme events in the form of droughts and floods. Changes in temperature 
and rainfall patterns coupled with other components of climate change are influencing changes in vegetative species diversity in general and species richness in particular. This study has shown that there is a relationship between vegetative species diversity and climate change and this provides a platform for countries to devise strategies to enhance the resilience of ecosystems to climatic changes through the adoption of species based adaptive and mitigation strategies according to the Sustainable Development Goals (SDGs). It has also been established that, besides being a good indicator of water content in leaves, the Normalised Difference Water Index (NDWI) is a useful proxy indicator of species diversity, specifically species richness. The inter-cellular air spaces of the spongy mesophyll layer of leaves contain varying amounts of water depending on the type of species. These variations as captured by NDWI can inform about the variety of species found in an ecosystem. Thus, NDWI can be used to assess the impact of climate change on species diversity. The availability of free satellite images provides an incentive to monitor species diversity over time even in areas where there is no record of species diversity data. However, NDWI should not be used alone when performing diversity assessment, other biophysical variables such as temperature and rainfall play an important role in buttressing and validating the utility of NDWI.

\section{References}

Beaumont, LJ., Pitman, A., Perkins, S., Zimmermann, NE., Yoccoz, NG. \& Thuiller, W 2011. 'Impacts of climate change on the world's most exceptional ecoregions', PNAS, vol. 108, no.6, pp. 2306-2311.

Bellard C., Bertelsmeier C., Leadley P., Thuiller W., Courchamp F 2012, 'Impacts of climate change on the future of biodiversity', Ecology letters, vol.15, no 4, pp. 365-377.

Chander G, Brian L, Helder D.L. 2009. 'Summary of current radio metric calibration coefficients for Landsat MSS, TM, ETM+, and EO-1 ALI sensors', Remote Sensing of the Environment, Vol. 113 pp.893-903.

Chikodzi D. and Mutowo G. 2014. 'Analysis of climate change signatures on micro-catchments as a means of understanding drying up of wetlands: The case of Mutubuki wetlands in Gutu district of Zimbabwe'. Ethiopian Journal of Environmental Studies \& Management, Vol. 7, no 2, pp.821 - 831.

Christensen, J.H., Hewitson, B., Busuioc, A., Chen, A., Gao, X., Held, I., Jones, R., Kolli, R.K., Kwon, W.T., Laprise, R., Magaña Rueda, V., Mearns, L., Menéndez, C.G., Räisänen, J., Rinke, A., Sarr, A., Whetton, P., 2007. 'Regional climate projections'. In: Solomon, S., Qin, D., Manning, M., Chen, Z., Marquis, M., Averyt, K.B., Tignor, M., Miller, H.L. (Eds.), Climate Change 2007: The Physical Science Basis. Contribution of Working Group I to the Fourth Assessment Report of the Intergovernmental Panel on Climate Change. Cambridge University Press, Cambridge. 
Davis, S.D., Heywood,V.H., and Hamilton,A.C. 1994. 'Centres of plant diversity. A guide and strategy for their conservation', IUCN Publications Unit, Cambridge.

Dawson, T.P., Jackson, S.T., House, J.I., Prentice, I.C. \& Mace, G.M. 2011. 'Beyond predictions: biodiversity conservation in a changing climate'. Science, 332, pp53-58.

Delong, D. C. 1996. 'Defining biodiversity'. Wildlife Society Bulletin. Vol. 2. No.4, pp.81-97.

Diamond J. 1988. 'Factors controlling species diversity: Overview and synthesis'. Annals of the Missouri botanical Garden No.75:117-129

Dietz, E.J. and Killeen, T.J. 1981. 'A nonparametric multivariate test for monotone trend with pharmaceutical applications'. Journal of the American Statistical Association, No. 76, pp 169-174.

Dillon, M.E., Wang, G. \& Huey, R.B. 2010. 'Global metabolic impacts of recent climate warming'. Nature, No.467, 704-706.

Dore, M.H.I., 2005. Climate change and changes in global rainfall patterns: What do we know? Environment International Vol.31, No. 8, pp.1167-1181.

Ellis, J., Price, P., Boone, R., Yu, F., Togtohyn, C., \& Yu, M. 2001. Integrated assessment of climate change effects on steppe vegetation in Mongolia and Inner Mongolia. In T. Chuluun \& D. Ojima (Eds.), Fundamental issues affecting sustainability of the Mongolian Steppe. Ulaanbaatar, Mongolian Academy of Sciences.

Gao B.C. 1996, 'NDWI-A normalised difference water index for remote sensing of vegetation liquid water from space', Remote sensing of Environment, Elsevier, Vol. 58 pp 257-266.

Gilman, S.E., Urban, M.C., Tewksbury, J., Gilchrist, G.W. \& Holt, R.D. 2010. 'A framework for community interactions under climate change'. Trends in Ecological Evolution. Vol.25, pp.325331.

Gu Y, Brown J. F., Verdin J. P., and Wardlow B. 2007. 'A five-year analysis of MODIS NDVI and NDWI for grassland drought assessment over the central Great Plains of the United States, Geophysical Research Letters, VOL. 34, pp.1-6

Hamed, K.H. and Rao, A.R. 1998. A modified Mann-Kendall trend test for auto correlated data. Journal of Hydrology. Vol. 204, pp.182-196.

Hannah, L. 2001. 'The role of a global protected areas system in conserving biodiversity in the face of climate change' In Visconti G. and Balaban M.(eds). Climate change and protected areas, Kluwer, Dordrecht.

Hannah, L., Midgley, G.F., Lovejoy, T., Bond, W.J., Bush, M.L., Scott, D. \& Woodward, F.I. 2002 Conservation of biodiversity in a changing climate. Conservation Biology, Vol 16, pp.11-15.

Hansen, J., Ruedy, R., Sato, M., Lo, K., 2010, 'Global surface temperature change', Reviews of Geophysics, Vol.103, No. 39, pp 14288-14293.

Hirsch, R.M., Helsel, D.R., Cohn, T.A. and Gilroy, E. J. 1993. Statistical analysis of hydrologic data. McGraw Hill, New York. 
Hughes, L. 2000 'Biological consequences of global warming: is the signal already apparent'? Trends in Ecology and Evolution, Vol. 15, 56-61.

IPCC 2001 Climate change 2001: impacts, vulnerability and adaptation. Contribution of Working Group II to the Third Assessment Report of the Intergovernmental Panel on Climate Change. IPCC Working Group 2, Cambridge University Press, Port Chester, NY.

IPCC, 2007. Climate change 2007: the physical science basis. In: Solomon, S., Qin, D., Manning, M., Chen, Z., Marquis, M., Averyt, K.B., Tignor, M., Miller, H.L. (Eds.), Contribution of Working Group I to the Fourth Assessment Report of the Intergovernmental Panel on Climate Change. Cambridge University Press, Cambridge.

Jackson T.J., Chen, D., Cosh M., Li F, Anderson M, Walthall C, Doriaswamy P, Hunt E.R. 2004. 'Vegetation water content mapping using Landsat data derived normalized difference water index for corn and soybeans', Remote Sensing of Environment, Vol.92, pp. 475-482.

John R, Jiquan C, Nan L, Ke G, Cunzhu L, Yafen W, Asko N, Keping M, Xingguo H. 2008 'Predicting plant diversity based on remote sensing products in the semi-arid region of Inner Mongolia', Remote sensing of Environment, Vol. 112 , pp.2018-2032.

John R., Chen J., Kim Y., Ou-yang Z., Xiao J., Park H., Shao C., Zhang Y., Amarjargal A., Batkhshig O., Qi J 2015 'Differentiating anthropogenic modification and precipitation-driven change on vegetation productivity on the Mongolian Plateau', Landscape ecology, Vol.31, pp.547-566

Kruger, A.C., Shongwe, S., 2004. Temperature trends in South Africa: 1960-2003. International Journal of Climatology Vol.24, pp. 1929-1945.

Kusangaya, S., et al. Impacts of climate change on water resources in southern Africa: A review. Journal of Physics and Chemistry of the Earth. Vol 67, pp 47-54

Lenihan J. M., Drapek R., Bachelet D and Neilson R. P. 2003. Climate change effects on vegetation, carbon and fire in California. Ecological applications, Vol. 13, No.6, pp.1667-1681.

Lettenmaier, D.P. 1976. Detection of trends in water quality data from records with dependent observations. Water Resources, Vol.12, No.5, pp.1037-1046.

Mann, H.B.1945. Non-parametric tests against trend. Econometrica, Vol 13, pp. 245-259.

Makarau, A. 1995. Intra-seasonal oscillatory models of the southern Africa summer circulation. PhD Thesis, University of Cape Town, South Africa.

Mazvimavi, D. 2010. Climate Change, Water Availability and Supply. In Kotecha, P.(Ed.), Climate Change, Adaptation and Higher Education: Securing our future. SARUA Leadership Dialogue Series, vol. 2, no. 4, pp. 81-10

McMahon, S.M., Harrison, S.P., Armbruster, W.S., Bartlein, P.J., Beale, C.M., Edwards, M.E. et al. 2011. Improving assessment and modelling of climate change impacts on global terrestrial biodiversity. Trends in Ecological Evolution. Vol.26, pp.249-259.

Michelle D., Staudinger, N. B., Grimm, A. S., Shawn L. Carter, F. Stuart C, Peter K., Mary R., Bruce A. S. 2012. Impacts of Climate Change on Biodiversity, Ecosystems, and Ecosystem Services: 
Technical Input to the 2013 National Climate Assessment. Cooperative Report to the 2013 National Climate Assessment.

Mitchell, 2007, Quantitative analysis by the point-centred quarter method, Hobart and William Smith Colleges, Geneva.

Mutke, J., Kier, G., Braun, G., Schultz, C. and Barthlott,W. 2001. 'Patterns of African vascular plant diversity - a GIS based analysis'. Systematics and Geography of Plants. Vol. 71, pp. 1125-36

Mutowo G and Murwira A. 2012 ' Relationship between remotely sensed variables and tree species diversity in savanna woodlands of Southern Africa', International Journal of Remote Sensing, Vol. 33, No 20, pp.6378-6402.

New, M., Hewitson, B., Stephenson, D.B., Tsiga, A., Kruger, A., Manhique, A., Gomez, B., Coelho, C.A.S., Masisi, D.N., Kululanga, M.E., Adesina, F., Saleh, H., Kanyanga, J., Adosi, J., Bulane, L., Fortunata, L., Mdoka, M.L., Lajoie, R., 2006. 'Evidence of trends in daily climate extremes over Southern and West Africa'. Journal of Geophysics Research, Vol. 111, pp. 1-11.

Parmesan, C. 2006. 'Ecological and evolutionary responses to recent climate change'. Ecology and Evolution. Vol.37, pp. 637-669.

Parmesan, C. and Yohe G. 2003. 'A globally coherent fingerprint of climate change impacts across natural systems'. Nature, Vol. 421, pp.37-42.

Pereira, H.M., Leadley, P.W., Proenca, V., Alkemade, R., Scharlemann, J.P.W., FernandezManjarres, J.F. 2010. ' Scenarios for global biodiversity in the 21st century'. Science, Vol. 330, pp.1496-1501.

Perrings C. 2010. Biodiversity, Ecosystem Services and Climate change. The economic problem, Environmental economics series paper number 120.

Root, B.A., Price, J.T. \& Hall, K. 2003. Fingerprints of global warming on wild animals and plants. Nature, Vol.421, pp. 47-60.

Sala, O. E., Lauenroth,W. K., \& Golluscio, R. A.1997. Plant functional types in temperate semi-arid regions. In T. M. Smith, H. H. Shugart, \& F. I. Woodward (Eds.), Plant functional types, Cambridge University Press, Cambridge.

Salamin, N., Wu"est, R.O., Lavergne, S., Thuiller, W. \& Pearman, P.B. 2010. Assessing rapid evolution in a changing environment. Trends in Ecological Evolution., Vol. 25, 692-698.

Schenk, H. J., \& Jackson, R. B. 2002. 'Rooting depths, lateral root spreads and belowground/above-ground allometries of plants in water-limited ecosystems'. Journal of Ecology, Vol 90, pp. $480-494$.

Schlesinger, W. H., \& Ehleringer, J. R. 2001. 'Water use trade-offs and optimal adaptations to pulse-driven arid ecosystems'. Journal of Ecology, Vol 89, pp. 464-480.

Simba F.M., Murwendo T., Chikodzi D., Mapurisa B., Munthali A., and Seyitini L., 2012. Environmental Change and Farm Productivity: An Assessment of Masvingo Province of Zimbabwe, Sacha Journal of Environmental Studies, Vol. 2. No.1, pp.114-129. 
Simba, F.M., Chikodzi, D., Murwendo, T. 2012. Climate change scenarios, perceptions and crop production: a case study of Semi-arid Masvingo Province in Zimbabwe. Journal of Earth Science Climate Change, Vol. 3, No.3. pp 124-131.

Skidmore, A.K., Oindo, B.O. Said, M.Y., 2003. Biodiversity assessment by remote sensing. In Proceedings of the 30th International symposium on remote sensing of the environment: information for risk management and sustainable development, November 10-14, 2003, Honolulu, Hawaii.

Snyder, K. A., \& Williams, D. G. 2003. Defoliation alters water uptake by deep and shallow roots of Prosopis velutina (Velvet Mesquite). Functional Ecology, Vol. 17, pp. 363-374.

Swingland I. R. 2001. Biodiversity, definition of, Encyclopaedia of Biodiversity, Vol. 1, Academic press.

Tewksbury, J.J., Huey, R.B. \& Deutsch, C.A. 2008. Ecology - Putting the heat on tropical animals. Science, Vol.320, pp.1296-1297.

Unganai, L., 1996. 'Historic and future climatic change in Zimbabwe', Climate research, Vol. 6, pp $137-145$.

Urban, D.A., 2002. Tactical monitoring of landscapes. Integrating landscape ecology into natural resource management. Cambridge University Press, Cambridge.

Von Storch, H. 1995. Misuses of statistical analysis in climate research In: Analysis of Climate Variability: Applications of Statistical Techniques. Springer-Verlag, Berlin, Germany.

Walker R.E., Stoms D.M., Estes J.E. and Cayocca K.D. 1992. Relationships between biological diversity and multi-temporal vegetation index data in California. ASPRS ACSM held in Albuquerque, New Mexico, Vol 3, pp 562-571.

Warburton, M.L., Schulze, R.E., 2005. Detection of climate change: a review of literature on changes in temperature, rainfall and streamflow, on detection methods and data problems. In: Schulze, R.E. (Ed.), Climate Change and Water Resources in Southern Africa: Studies on Scenarios, Impacts, Vulnerabilities and Adaptation. Water Research Commission, Pretoria, South Africa.

Warburton, M.L., Schulze, R.E., Maharaj, M., 2005. Is South Africa's temperature changing? An analysis of trends from daily records, 1950-2000. In: Schulze, R.E. (Ed.), Climate Change and Water Resources in Southern Africa: Studies on Scenarios, Impacts, Vulnerabilities and Adaptation. Water Research Commission, Pretoria, South Africa

Zhou, N. M. 2004. Vegetation Soil Relationships as Aids to Soil Survey in Semi-Arid Areas. A thesis submitted in partial fulfilment of the requirements for the degree of Doctor of Philosophy. Department of Soil Science and Agricultural Engineering. Faculty of Agriculture. University of Zimbabwe. 